\title{
$\mathrm{BMJ}$
}

\section{Accuracy of reading liquid based cytology slides using the ThinPrep Imager compared with conventional cytology: prospective study}

\author{
Elizabeth Davey, research fellow, Jefferson d'Assuncao, research officer, ${ }^{1}$ Les Irwig, professor of \\ epidemiology, ${ }^{1}$ Petra Macaskill, associate professor of biostatistics, ${ }^{1}$ Siew FChan, statistical research officer, ${ }^{1}$ \\ Adele Richards, cytology manager, ${ }^{2}$ Annabelle Farnsworth medical director ${ }^{2}$
}

Screening and Test Evaluation Program, School of Public Health, University of Sydney, NSW 2006, Australia

${ }^{2}$ Cytology Department, Douglass Hanly Moir Pathology, North Ryde, NSW, Australia

Correspondence to: E Davey daveye@health.usyd.edu.au

doi:10.1136/bmj.39219.645475.55

\section{ABSTRACT}

Objective To compare the accuracy of liquid based cytology using the computerised ThinPrep Imager with that of manually read conventional cytology.

Design Prospective study.

Setting Pathology laboratory in Sydney, Australia.

Participants 55164 split sample pairs (liquid based sample collected after conventional sample from one collection) from consecutive samples of women choosing both types of cytology and whose specimens were examined between August 2004 and June 2005.

Main outcome measures Primary outcome was accuracy of slides for detecting squamous lesions. Secondary outcomes were rate of unsatisfactory slides, distribution of squamous cytological classifications, and accuracy of detecting glandular lesions.

Results Fewer unsatisfactory slides were found for imager read cytology than for conventional cytology $(1.8 \% \mathrm{~V}$ $3.1 \%$; $\mathrm{P}<0.001)$. More slides were classified as abnormal by imager read cytology $(7.4 \% \mathrm{v} 6.0 \%$ overall and $2.8 \% \mathrm{~V}$ $2.2 \%$ for cervical intraepithelial neoplasia of grade 1 or higher). Among 550 patients in whom imager read cytology was cervical intraepithelial neoplasia grade 1 or higher and conventional cytology was less severe than grade 1, 133 of 380 biopsy samples taken were high grade histology. Among 294 patients in whom imager read cytology was less severe than cervical intraepithelial neoplasia grade 1 and conventional cytology was grade 1 or higher, 62 of 210 biopsy samples taken were high grade histology. Imager read cytology therefore detected 71 more cases of high grade histology than did conventional cytology, resulting from 170 more biopsies. Similar results were found when one pathologist reread the slides, masked to cytology results.

Conclusion The ThinPrep Imager detects 1.29 more cases of histological high grade squamous disease per 1000 women screened than conventional cytology, with cervical intraepithelial neoplasia grade 1 as the threshold for referral to colposcopy. More imager read slides than conventional slides were satisfactory for examination and more contained low grade cytological abnormalities.

\section{INTRODUCTION}

Although manual checking of conventional cervical smears has been used for decades to screen for cervical cancer and precancerous cells, liquid based cytology is replacing conventional cytology in many countries. The potential advantages of liquid based cytology are adjunctive testing, including testing for human papillomavirus; faster reading times; and cost saving of automation. Evidence is insufficient, however, to confirm that liquid based cytology is more accurate than conventional cytology, ${ }^{1}$ which continues to be widely used.

Conventional cytology involves the transference of cervical material from a collection instrument on to a glass slide whereas liquid based cytology (for example, the ThinPrep Liquid-based Cytology Preparation system, Cytyc, Marlborough, MA) involves rinsing the collection instrument in liquid to produce a suspension, which is processed in a laboratory to produce a monolayer of cells. The ThinPrep Imager (Cytyc) system, a computerised system for reading slides, is a new technology applied to liquid based cytology. The imager identifies 22 fields of interest most likely to contain abnormal cells, which are then examined by a cytologist.

As liquid based cytology has not been approved for government funding in Australia ${ }^{2}$ it is sometimes carried out as an additional test within a split sample specimen, whereby a conventional cytology slide is made first and then the collection instrument is rinsed in transport medium and the suspension used to make a liquid based cytology slide. In countries where liquid based cytology is used, samples are usually taken as "direct to vial" specimens, in which all cervical material collected is used to produce the slide. Liquid based cytology slides prepared as split samples might be at a disadvantage for quality and accuracy compared with direct to vial slides because residual material is used. The Douglass Hanly Moir pathology laboratory has offered manual reading of split sample liquid based cytology (ThinPrep) specimens for nine years. It recently introduced the ThinPrep Imager system. The laboratory provides services for about 200000 
women (age range 16-80 years) annually. These women are representative of the general population. Over $80 \%$ of cervical cytology evaluated at the laboratory is for screening purposes and the remainder for diagnosis.

Our main aim was to compare the accuracy of liquid based cytology using the ThinPrep Imager with that of conventional cytology in detecting squamous lesions. Secondary outcomes were the rate of unsatisfactory slides, the distribution of squamous cytological classifications, and accuracy in detecting glandular lesions.

\section{METHODS}

To compare the accuracy of liquid based cytology using the ThinPrep Imager with conventional cytology we cross classified independently read imager read cytology and conventional squamous cytology and measured the proportion with cervical intraepithelial neoplasia of grade 2 or more severe histology. This was carried out among slides showing positive results with imager read cytology and negative results with conventional cytology and slides showing negative results with imager read cytology and positive results with conventional cytology. For paired smears the estimation of the difference in true positives detected by one smear compared with another does not require verification of concordant results. ${ }^{34}$ We considered the results to be concordant if they were identical between two slides or if the recommendations for clinical management ${ }^{5}$ were the same for both results.

We obtained histology results for discordant cytology from the New South Wales Pap test register, which keeps records of the results from $99 \%$ of women with cervical cytology and histology undertaken in New South Wales. Because management of the women in this study, including decisions about colposcopy and biopsy, occurred within the context of routine clinical practice, not all the women will have had biopsies. This incomplete verification should not introduce bias if management decisions are masked to the type of cytology slide showing the more severe abnormality and if the proportion of women who had biopsies was the same in matched discordant cells.

As histology reports from the Pap test register were issued by pathologists with access to the cytology reports, we sought all histological slides where cytology was discordant. for rereading by a pathologist $(\mathrm{AF})$, unaware of the results from cytology and the register so as to provide an unbiased reference standard. To reduce misclassification we also analysed study findings using the more severe results from the register and the masked reread results as the reference standard. Hence we used three specific reference standards to compare results between liquid based cytology and conventional cytology.

\section{Characteristics of specimens and cytologists}

Inclusion criteria for our study were consecutive cervical specimens taken from women of any age who chose to have a ThinPrep liquid based cytology sample taken in addition to a conventional cytology sample, and whose specimens were sent to the pathology laboratory for examination between August 2004 and June 2005. We included smear tests done for both screening and investigations.

Specimens were obtained, handled, and read under routine conditions and all were collected by the split sample technique. We have no data on the types of collection instruments used: the Cervex-Brush (Rovers Medical Devices, Oss, Netherlands), with or without an endocervical brush, is widely used in Australia.

The study cytologists held the qualification of cytotechnologist (Australian Society of Cytology). Those who evaluated the imager read slides had also undertaken a three day training course in manual reading of ThinPrep slides and a one day course on the use of the imager. The cytologists' experience ranged from 2.040.0 years (median 17.0 years; interquartile range 7.023.0 years), with no important differences between those who did and did not also read liquid based cytology slides. Experience in reading liquid based cytology slides ranged from 2.0-8.0 years (median 7.0 years; interquartile range 5.5-8.0 years).

\section{Cytology}

Liquid based cytology slides were initially read by the ThinPrep Imager. The 22 fields of interest were examined manually by a cytologist, using an automated microscope to locate possible abnormalities. Conventional cytology slides were read manually by a cytologist. The same evaluation process was then followed independently for both types of slide. Those considered normal were reported as such. If a slide was unsatisfactory or abnormal it was rescreened by a more experienced cytologist. If, after review and discussion, the cytologists reached consensus that a slide was unsatisfactory or normal, it was reported as such. If the cytologists agreed that a slide was satisfactory for examination but could not reach consensus about normality (for example, high grade squamous intraepithelial lesions versus normal), the slide was reviewed by a pathologist. The pathologist's diagnosis provided the report for satisfactory slides in which one or both cytologists found an abnormality. Thus two reports were made, through an identical and independent process, for each pair of slides: one for the imager read slide and one for the conventional cytology slide. Cytologists and pathologists were masked to the cytology report on the other slide of the pair.

The final cytology report issued to the referring clinician showed the worse abnormality reported for either slide of the pair. If both contained any abnormality the report stated that both the imager read slide and conventional cytology slide showed the final result. Hence the clinician's decision to refer to colposcopy in these cases and the colposcopist's decision to carry out a biopsy was made using a final cytology result that did not identify which technology yielded the more severe abnormality and was, therefore, unbiased. If one slide appeared normal and the other showed an abnormality, the identity of the technology used to detect the 
abnormality was stated on the final report for the referring clinician.

Cytology reports were classified using the Australia modified Bethesda system 1994, the reporting system in use during the study. Comparison between this classification, the Bethesda 2001 system, and British system is available at www.health.usyd.edu.au/step/ publications/imager_appendix.pdf.

We cross tabulated the cytology pairs according to whether they were satisfactory or unsatisfactory for examination. Pairs with satisfactory slides were cross tabulated according to their squamous cytology results. We used the threshold of cervical intraepithelial neoplasia grade 1 to determine positive and negative cytology for analyses of the accuracy of squamous cytology, because guidelines current during the study recommended referral of women with reports of cervical intraepithelial neoplasia of grade 1 or more severe cytology for colposcopy.

\section{Histology}

For discordant squamous cytology pairs we sought the histology reports from the Pap test register until six months after the date of cytology. In cases where more than one histology specimen was taken, we used the most severe result. We used standard cervical intraepithelial neoplasia terminology for histology reports from the register and for the results of slides that were reread.

We then cross tabulated and examined the histology results from the register with those of the masked rereadings for agreement.

To determine positive and negative reference standards for squamous histology, we used a histology threshold of cervical intraepithelial neoplasia grade 2 , as disease of this severity or greater was considered clinically important. Cervical intraepithelial neoplasia grade 1 or less severe histology was therefore categorised as reference standard negative whereas cervical intraepithelial neoplasia grades 2 or 3 or carcinoma histology were categorised as reference standard positive in all analyses.

For discordant cytology results we calculated the numbers of reference standard positive and reference standard negative cases for the imager read slides and conventional cytology slides using cervical intraepithelial neoplasia grade 1 as the threshold. In this way we could compare the difference in the number of biopsies and the detection of high grade squamous histology between the two types of slides. We used the same methods for the additional analyses, using

\begin{tabular}{|c|c|c|c|}
\hline Classification & $\begin{array}{l}\text { Satisfactory by conventional } \\
\text { cytology }\end{array}$ & $\begin{array}{l}\text { Unsatisfactory by } \\
\text { conventional cytology }\end{array}$ & Total \\
\hline Satisfactory by imager reading & 52665 & 1517 & $54182(98.2)$ \\
\hline Unsatisfactory by imager reading & 795 & 187 & $982(1.8)$ \\
\hline Total & $53460(96.9)$ & $1704(3.1)$ & 55164 \\
\hline
\end{tabular}

rereading of the slides as a reference standard and the more severe of the histology results from the Pap test register and masked rereading results.

The process by which discordant slide pairs were derived, and biopsies and Pap test register histology results were compared, is available at www.health. usyd.edu.au/step/publications/imager_appendix.pdf. An identical process was undertaken for the additional analyses.

\section{Glandular cytology and histology}

Satisfactory slide pairs (both containing endocervical components) were cross tabulated according to classification of glandular cells. We examined the accuracy of abnormal glandular cytology at two cytology thresholds: glandular atypia and glandular inconclusive. We considered reports of adenocarcinoma in situ or adenocarcinoma as reference standard positive and reports of negative glandular histology as reference standard negative.

\section{Statistical analyses}

We used McNemar's test to determine whether the proportions of unsatisfactory slides differed between imager read cytology and conventional cytology. This method was also used to compare the accuracy of the two types of slide (cervical intraepithelial neoplasia grade 1 as threshold) for the detection of high grade histology.

We compared the distribution of cytology classifications for both types of slide using a logistic generalised estimating equation model to take account of the pairing of results for each slide. The outcome variable was slide type, with test result fitted as a categorical explanatory variable.

\section{RESULTS}

Overall, 55164 split sample pairs (liquid based slide obtained after conventional cytology slide from one collection) were evaluated to compare the accuracy of liquid based cytology slides read using the ThinPrep Imager with that of manually read conventional cytology slides.

Fewer slides were found to be unsatisfactory when read by the Imager than when read manually by conventional cytology: $982 \quad(1.8 \%)$ v $1704 \quad(3.1 \%)$; $\chi^{2}=225.5, \mathrm{df}=1, \mathrm{P}<0.001$. Both imager read slides and conventional cytology slides were satisfactory in 52665 pairs (table 1 ).

Table 2 shows the squamous classifications of the slides when cross tabulated. The distribution across classifications differed between imager read cytology and conventional cytology $\left(\chi^{2}=402.5, \mathrm{df}=6, \mathrm{P}<0.001\right)$. The ThinPrep Imager labelled more slides as containing low grade abnormalities than did conventional cytology. The imager was more likely than conventional cytology to classify slides as atypia, (odds ratio $1.08, \mathrm{P}=0.018$ ), atypia with signs of human papillomavirus infection $(1.65, \mathrm{P}<0.001)$, and cervical intraepithelial neoplasia grade $1(1.47, \mathrm{P}<0.001)$, grade 2 $(1.45, \mathrm{P}<0.001)$, and grade $3(1.15, \mathrm{P}=0.019)$, whereas 
Table 2 | Squamous classification of cytology. Numbers in parentheses are percentages

\begin{tabular}{|c|c|c|c|c|c|c|c|c|c|}
\hline \multirow[b]{2}{*}{ Classification } & \multicolumn{7}{|c|}{ Outcome by conventional cytology } & \multirow[b]{2}{*}{ Total } & \multirow[b]{2}{*}{ Odds ratio $\neq(95 \% \mathrm{Cl})$} \\
\hline & Normal & Atypia & $\begin{array}{c}\text { Atypia with } \\
\text { HPV* }^{*}\end{array}$ & CIN1 & Inconclusive $†$ & CIN2 & $\mathrm{CIN} \geq 3$ & & \\
\hline \multicolumn{10}{|l|}{$\begin{array}{l}\text { Outcome by } \\
\text { imager reading }\end{array}$} \\
\hline Normal & $47688 \S$ & $796 \S$ & 88 & 47 & 111 & 2 & 14 & $48746(92.6)$ & 0.99 (0.98 to 0.99$)$ \\
\hline Atypia & $1071 \S$ & $381 \S$ & 59 & 44 & 33 & 15 & 6 & $1609(3.1)$ & 1.08 (1.01 to 1.15$)$ \\
\hline $\begin{array}{l}\text { Atypia } \\
\text { with HPV* }\end{array}$ & 376 & 133 & $241 \S$ & $84 \S$ & 12 & 4 & 6 & $856(1.6)$ & 1.65 (1.51 to 1.80$)$ \\
\hline CIN1 & 179 & 117 & $110 \S$ & $264 \S$ & 27 & 58 & 6 & $761(1.4)$ & 1.47 (1.35 to 1.60$)$ \\
\hline Inconclusive* & 98 & 29 & 2 & 15 & $45 \S$ & 6 & 27 & $222(0.4)$ & $0.78(0.67$ to 0.92$)$ \\
\hline CIN2 & 37 & 26 & 15 & 53 & 18 & $35 \S$ & $29 \S$ & $213(0.4)$ & 1.45 (1.20 to 1.75$)$ \\
\hline $\mathrm{CIN} \geq 3$ & 30 & 12 & 5 & 11 & 37 & $27 \S$ & $136 \S$ & $258(0.5)$ & 1.15 (1.02 to 1.30$)$ \\
\hline Total & $\begin{array}{c}49479 \\
(94.0)\end{array}$ & $\begin{array}{l}1494 \\
(2.8)\end{array}$ & $520(1.0)$ & $518(1.0)$ & $283(0.5)$ & $147(0.3)$ & $224(0.4)$ & $52665(100)$ & \\
\hline
\end{tabular}

$\mathrm{HPV}=$ human papillomavirus; $\mathrm{CIN}=$ cervical intraepithelial neoplasia.

*Atypia with signs of HPV infection.

†nconclusive, high grade histology to be excluded.

$\ddagger$ Ratio of imager read slides to conventional cytology slides.

imager read cytology was less likely than conventional cytology to classify slides as inconclusive, high grade histology to be excluded $(0.78, \mathrm{P}=0.0028)$.

Accuracy of cervical intraepithelial neoplasia grade 1 or more severe cytology to detect grade 2 or more severe histology

When accuracy was compared among the three reference standards (histology recorded in Pap smear test register, masked rereading of histology, and more severe of these results) imager read cytology detected significantly more high grade histology than did conventional cytology, irrespective of reference standard used.

\section{Pap test register histology as reference standard}

The derivation of histology results in the Pap test register from discordant cytology is available at www. health.usyd.edu.au/step/publications/imager_appen dix.pdf..

Of 550 cytology pairs in which the imager read slide was reported as cervical intraepithelial neoplasia grade 1 or more severe histology and the conventional cytology slide was reported as less severe than grade 1 (table 3), 380 biopsy samples (69.1\%) were available (table 4). Of 294 cytology pairs in which the conventional cytology slide was reported as cervical intraepithelial neoplasia grade 1 or more severe histology and the imager read slide was less severe than grade 1 , 210 biopsies $(71.4 \%)$ were available. These percentages of discordant cytology cases with histology results in the Pap test register from biopsy samples did not differ $\left(\chi^{2}=0.50, \mathrm{df}=1, \mathrm{P}=0.48\right)$. Histology rates were similar for more detailed cytology cross tabulation, for discordant pairs where at least one result was cervical intraepithelial neoplasia grade 1 or more severe histology, and for the subset in which one slide of each pair was normal and the other was cervical intraepithelial neoplasia grade 1 or more severe histology (available at www.health.usyd.edu.au/step/ publications/imager_appendix.pdf).

Among the 380 histology results from the Pap test register that were positive by imager read cytology and negative by conventional cytology, 133 cases (24\%) of histological disease of cervical intraepithelial neoplasia grade 2 or more severe histology were detected (table 4). Among the 210 histology results from the Pap test register that were negative by imager read cytology and positive by conventional cytology, 62 cases $(21 \%)$ of histological high grade disease were detected (table 4$)$. The ThinPrep Imager therefore detected 71 (133 minus 62) more cases of histological high grade disease and required 170 (380 minus 210) more biopsy specimens to detect these cases. This increased detection was statistically significant $\left(\chi^{2}=77.6, \mathrm{df}=1, \mathrm{P}<0.001\right)$.

\section{Masked rereading of histology as reference standard}

Of 550 cytology pairs in which the imager read slide was reported as cervical intraepithelial neoplasia grade 1 or more severe, 280 histology slides $(50.9 \%)$ were reread (table 4). Of 294 cytology pairs in which the conventional cytology slide was reported as cervical intraepithelial neoplasia grade 1 or more severe, 154 histology slides $(52.4 \%)$ were reread. These percentages did not differ $\left(\chi^{2}=0.17, \mathrm{df}=1, \mathrm{P}=0.68\right)$. Among

\begin{tabular}{|c|c|c|}
\hline \multicolumn{3}{|c|}{$\begin{array}{l}\text { Table } 3 \mid \text { Number of cases of discordant cytology dichotom } \\
\text { across cervical intraepithelial neoplasia grade } 1 \text { cytology } \\
\text { threshold }(n=1758)\end{array}$} \\
\hline & \multicolumn{2}{|c|}{ Conventional cytology } \\
\hline & <CIN1 & $\mathrm{CIN} \geq 1$ \\
\hline \multicolumn{3}{|c|}{ Imager read cytology: } \\
\hline$<\mathrm{CIN1}$ & $656^{*}$ & 294 \\
\hline $\mathrm{CIN} \geq 1$ & 550 & $258^{\star}$ \\
\hline
\end{tabular}

$\mathrm{CIN}=$ cervical intraepithelial neoplasia.

*Cytology pairs that are discordant in table 2 and in which both slides are either less severe than CIN1 or are CIN1 or more severe. 
Table 4 | High grade histology results for discordant cytology

\begin{tabular}{|c|c|c|c|c|c|c|c|c|c|}
\hline \multirow[b]{3}{*}{ Discordant cytology* } & \multicolumn{9}{|c|}{ Reference standard } \\
\hline & \multicolumn{3}{|c|}{ PTR report } & \multicolumn{3}{|c|}{ Rereading result } & \multicolumn{3}{|c|}{$\begin{array}{c}\text { More severe of PTR report and } \\
\text { rereading result }\end{array}$} \\
\hline & $\begin{array}{l}\text { No of } \\
\text { slides }\end{array}$ & $\begin{array}{c}\% \text { of } \\
\text { discordant } \\
\text { cytology }\end{array}$ & $\begin{array}{c}\% \text { of } \\
\text { histology }\end{array}$ & $\begin{array}{l}\text { No of } \\
\text { slides }\end{array}$ & $\begin{array}{c}\text { \% of } \\
\text { discordant } \\
\text { cytology }\end{array}$ & $\begin{array}{c}\% \text { of } \\
\text { histology }\end{array}$ & $\begin{array}{l}\text { No of } \\
\text { slides }\end{array}$ & $\begin{array}{c}\text { \% of } \\
\text { discordant } \\
\text { cytology }\end{array}$ & $\begin{array}{c}\% \text { of } \\
\text { histology }\end{array}$ \\
\hline \multicolumn{10}{|l|}{$\begin{array}{l}\text { Imager read slide positive, } \\
\text { conventional slide } \\
\text { negative: }\end{array}$} \\
\hline Discordant cytology* & 550 & - & - & 550 & - & - & 550 & - & - \\
\hline Histology obtained & 380 & 69.1 & - & 280 & 50.9 & - & 380 & 69.1 & - \\
\hline High grade histology† & 133 & 24.2 & 35.0 & 153 & 27.8 & 54.6 & 196 & 35.6 & 51.6 \\
\hline \multicolumn{10}{|l|}{$\begin{array}{l}\text { Imager read slide negative, } \\
\text { conventional slide } \\
\text { positive: }\end{array}$} \\
\hline Discordant cytology* & 294 & - & - & 294 & - & - & 294 & - & - \\
\hline Histology obtained & 210 & 71.4 & - & 154 & 52.4 & - & 210 & 71.4 & - \\
\hline High grade histology† & 62 & 21.1 & 29.5 & 68 & 23.1 & 44.2 & 90 & 30.6 & 42.9 \\
\hline
\end{tabular}

PTR=New South Wales Pap test register.

*Cervical intraepithelial neoplasia grade 1 cytology threshold.

†Cervical intraepithelial neoplasia grade 2 histology threshold.

the 280 histology slides reread for cytology pairs that were positive by imager read cytology and negative by conventional cytology, 153 cases $(27.8 \%)$ of cervical intraepithelial neoplasia grade 2 or more severe histology were detected (table 4). Among the 154 histology slides reread for cytology pairs that were negative by imager read cytology and positive by conventional cytology, 68 cases $(23.1 \%)$ of cervical intraepithelial neoplasia grade 2 or more severe histology were detected. Therefore liquid based cytology using the ThinPrep Imager detected 85 (153 minus 68) more cases of histological high grade disease than did conventional cytology and required 126 (280 minus 154) more biopsies to detect these cases (table 4). This increased detection was significant $\left(\chi^{2}=32.7, \mathrm{df}=1\right.$, $\mathrm{P}<0.001)$.

\section{More severe of Pap test register result and masked histology rereading as reference standard}

The record in the Pap test register and result of masked rereading of histology agreed in $81 \%$ of cases $(\kappa=0.62)$. To reduce misclassification the two histological assessments were combined, using the more severe of the two results as the reference standard. Imager read

\begin{tabular}{lccccc}
\hline Table 5| Glandular classification & \multicolumn{5}{c}{ Conventional cytology } \\
\cline { 2 - 7 } & $\begin{array}{l}\text { Normal } \\
\text { cytology }\end{array}$ & Atypia & Inconclusive* & $\begin{array}{c}\text { High grade } \\
\text { histology }\end{array}$ & Total \\
Imager read cytology: & $35536 \dagger$ & 27 & 9 & 4 & 35576 \\
\hline Normal & 9 & $3 \dagger$ & 0 & 1 & 13 \\
\hline Atypia & 2 & 1 & $0 \dagger$ & 1 & 4 \\
\hline Inconclusive* & 0 & 0 & 0 & $6 \dagger$ & 6 \\
\hline High grade histology & 35547 & 31 & 9 & 12 & 35599 \\
\hline Total & &
\end{tabular}

*Inconclusive, high grade histology to be excluded.

†Concordant cytology. cytology detected 106 (196 minus 90) more cases of histological high grade disease than did conventional cytology and required 170 (380 minus 210) more biopsies to detect these cases (table 4$)$. This increased detection was significant $\left(\chi^{2}=39.3, \mathrm{df}=1, \mathrm{P}<0.001\right)$.

\section{Glandular lesions}

Of 35599 cytology pairs in which both slides were satisfactory and contained endocervical components, only 63 pairs contained at least one abnormal slide (table 5). The imager labelled 23 slides and conventional cytology labelled 52 slides as glandular abnormalities. Of the 63 pairs containing abnormalities, 26 had results available in the Pap test register. Seventeen of 24 abnormal pairs with at least one slide reported as either inconclusive, high grade histology to be excluded or high grade glandular cytology had Pap test register results available, whereas 10 of 12 pairs with at least one slide reported as high grade had Pap test register results available. Six of the 26 histology reports were adenocarcinoma in situ $(\mathrm{n}=3)$ or adenocarcinoma $(\mathrm{n}=3)$. The remaining 20 were reported as normal histology for glandular lesions.

Cross tabulation of the 26 verified cases by cytology and histology results showed that all cases of adenocarcinoma in situ or adenocarcinoma were detected by both technologies at the cytology threshold of atypia (table 6). One case of high grade histology was detected only by conventional cytology at the cytology threshold of inconclusive, high grade histology to be excluded (table 6). This case would, however, have been referred for colposcopy on the basis of the squamous diagnoses of cervical intraepithelial neoplasia grade 3 for both imager read cytology and conventional cytology. Therefore all cases of high grade histology were detected by both technologies through referral to colposcopy on the basis of glandular or squamous cytological abnormality. 


\begin{tabular}{|c|c|c|c|c|}
\hline \multirow[b]{3}{*}{$\begin{array}{l}\text { Cytology threshold and } \\
\text { results }\end{array}$} & \multicolumn{4}{|c|}{ Glandular histology } \\
\hline & \multicolumn{2}{|c|}{$\begin{array}{c}\text { Adenocarcinoma in situ or } \\
\text { adenocarcinoma }\end{array}$} & \multicolumn{2}{|c|}{ Negative result } \\
\hline & $\begin{array}{c}\text { Negative by conventional } \\
\text { cytology }\end{array}$ & $\begin{array}{c}\text { Positive by } \\
\text { conventional } \\
\text { cytology }\end{array}$ & $\begin{array}{c}\text { Negative by } \\
\text { conventional } \\
\text { cytology }\end{array}$ & $\begin{array}{c}\text { Positive by } \\
\text { conventional } \\
\text { cytology }\end{array}$ \\
\hline \multicolumn{5}{|l|}{ Atypia: } \\
\hline $\begin{array}{l}\text { Negative by imager read } \\
\text { cytology }\end{array}$ & 0 & 0 & 0 & 12 \\
\hline $\begin{array}{l}\text { Positive by imager read } \\
\text { cytology }\end{array}$ & 0 & 6 & 4 & 4 \\
\hline \multicolumn{5}{|l|}{ Inconclusive*: } \\
\hline $\begin{array}{l}\text { Negative by imager read } \\
\text { cytology }\end{array}$ & 0 & 1 & 9 & 8 \\
\hline $\begin{array}{l}\text { Positive by imager read } \\
\text { cytology }\end{array}$ & 0 & 5 & 2 & 1 \\
\hline
\end{tabular}

\section{DISCUSSION}

Liquid based cytology slides obtained in a large population under routine clinical practice and read using the ThinPrep Imager detected significantly more histological high grade squamous disease than did manually read conventional cytology slides.

Although both technologies resulted in similar proportions of discordant cytology cases requiring biopsies $(69 \%$ for imager read cytology, $71 \%$ for conventional cytology), imager read cytology resulted in a significantly greater yield of high grade histology from these biopsies. Among discordant cytology of cervical intraepithelial neoplasia grade 1 or more severe histology, significantly more high grade histology (grade 2 or higher) was detected by imager read cytology than by conventional cytology using three reference standards: the histology results from the New South Wales Pap test register, masked rereading of histology by a pathologist, and the more severe of these two results.

The ThinPrep Imager detected 1.29 more cases of histological high grade disease per 1000 women screened than did conventional cytology. For each additional 100 cases of high grade histological disease detected by imager read cytology 240 biopsies would be required. When masked rereading of histology was used as the reference standard, 148 biopsies would be required for each additional 100 cases of high grade histological disease detected by imager read cytology.

This study provides a valid comparison of the accuracy of the technologies for several reasons. Firstly, we avoided reporting bias by using masked cytology reading and rereading of histology slides blinded to cytology results. Secondly, the incomplete verification by histology, which represents clinical decisions on whether or not colposcopy and biopsy were deemed necessary, was unbiased. When results of both slides were abnormal clinical decisions were unbiased because clinicians were masked to which technology detected the more severe abnormality. In cases in which one slide showed normal results and one abnormal results, referring clinicians were aware of which technology detected the abnormality, so decisions about colposcopy and biopsy were potentially not masked. However, we found no evidence that the proportions biopsied differed for results that were positive by imager read cytology and positive by conventional cytology in these cases. Thirdly, our finding of the improved accuracy of the ThinPrep Imager was consistent across three reference standards, designed to account for biases in non-masked evaluation of the Pap test register reference standard and reference standard misclassification. Fourthly, we used split sample specimens, in which the conventional cytology slide was prepared first, thereby potentially maximising the cellular content and improving the accuracy of conventional cytology. As split sample liquid based cytology specimens are made from residual material after the conventional cytology slide has been made, it seems likely that imager read cytology samples prepared using the direct to vial method would provide greater estimates of accuracy compared with conventional cytology samples.

Previous work comparing manually read liquid based cytology slides and conventional cytology slides is inconclusive because of the generally poor quality of studies. ${ }^{1}$ Although two studies compared the reading of slides using the ThinPrep Imager ${ }^{67}$ with manual reading of liquid based cytology slides, we could find no studies that directly compared the imager with conventional cytology.

In Australia 7.7 cases of histologically confirmed high grade cervical abnormalities per 1000 women screened are detected each year through a biennial Pap test screening programme using conventional histology. ${ }^{8}$ On the basis of the results of this study introduction of the ThinPrep Imager would increase detection by 1.3 cases per 1000 , to 9.0 cases per 1000 women screened, and would require 3.1 more biopsies per 1000 women screened to detect these cases.

Although some have claimed lower percentages of unsatisfactory slides for liquid based cytology than for conventional cytology, ${ }^{9-13}$ a systematic review comparing the two found no decrease over 46 studies. ${ }^{1}$ Fewer liquid based slides have been classified as unsatisfactory when read by the imager than when read manually. ${ }^{6}$ We found that the percentage of unsatisfactory imager read slides was 1.78\% compared with $3.09 \%$ for conventional slides. Therefore fewer women might be recalled for repeat smear tests than is currently the case if the ThinPrep Imager was introduced into population screening programmes. Whether the proportion of unsatisfactory slides would be similarly reduced in direct to vial liquid based cytology compared with conventional cytology should be explored.

In this study more squamous cytological abnormalities were found by imager read cytology than by conventional cytology, except for those classified in the category inconclusive, high grade histology to be excluded (ratio of imager read cytology to conventional cytology 0.8 ). This reduction in the number of 


\section{WHAT IS ALREADY KNOWN ON THIS TOPIC}

The accuracy of liquid based cytology read using an imager compared with manually read conventional cytology is not known

\section{WHAT THIS STUDY ADDS}

Liquid based slides read using the ThinPrep Imager detected 1.3 more cases of high grade disease per 1000 women screened than did manually read conventional slides

3.1 more biopsies per 1000 women screened were required to detect these cases

inconclusive slides read by the ThinPrep Imager may be explained by the improved preservation and concentration of cells in liquid based cytology samples. This finding should result in a reduction in the number of women requiring colposcopy.

Apart from cytology reports of cervical intraepithelial neoplasia grade 1 or more severe histology, which we examined against a histological reference standard, cytological abnormalities less severe than grade 1 were also reported in greater numbers by the ThinPrep Imager than by conventional cytology. The significant increase we found in cases of atypia, with or without signs of human papillomavirus infection, detected by the imager might reflect improved detection of abnormalities associated with oncogenic human papillomavirus types. ${ }^{14}$ The imager classified 8.6 more slides in these categories per 1000 women screened than did conventional cytology. However, it is estimated that about half of these abnormalities will regress to normal. ${ }^{15}$ The increased detection of low grade cytological lesions by the imager might result in higher rates of further testing. On the other hand, together with our finding of improved detection of histological cervical intraepithelial neoplasia grade 2 , it does raise the possibility that the increased detection of squamous abnormality by the imager might allow longer screening intervals. Models using our results and including clinical, economical, and psychological outcomes would help elucidate the potential impact of the introduction of the ThinPrep Imager and different screening intervals.

Although more glandular abnormalities were reported with conventional cytology than with the imager, the two were equivalent in detecting reference standard positive cases at a referral threshold of atypia. In one case the imager read slide was reported as low grade glandular atypia. However, as the squamous element was reported as cervical intraepithelial neoplasia grade 3 for both the imager read and conventional cytology slides, this woman would have been referred for colposcopy. The confusion between glandular and squamous high grade lesions is well described in conventional cytology but is also postulated in liquid based cytology samples because of the altered cytological appearances associated with fluid preservation. ${ }^{16}$ The decreased detection of cytological glandular lesions by the ThinPrep Imager in our study was not at the cost of reduced detection of histological glandular disease, although this result is limited by the small number of cases.
A study based on the same cytologists has shown that the mean time taken to evaluate and report liquid based slides using the ThinPrep Imager is 4.7 minutes per slide compared with 10.6 minutes per slide for conventional cytology. ${ }^{17}$ Through improved accuracy and faster reading times the ThinPrep Imager might confer both greater laboratory productivity and enhanced clinical outcomes, as well as offering the potential for human papillomavirus testing on the same sample.

This study of 55164 split sample pairs provides strong evidence that the ThinPrep Imager detects more high grade histological disease than does conventional cytology. The introduction of the imager would increase the detection of high grade histological disease by 1.3 cases per 1000 women screened.

We thank Rodney Ecclestone, Paul Jelfs, Yeqin Zuo, and staff of the Cancer Institute of New South Wales for their help in providing access to data in the New South Wales Pap test register; Colin Goldschmidt (Sonic Healthcare); the pathologists and cytologists of Douglass Hanly Moir Pathology for their very helpful contribution; staff at other pathology laboratories for their invaluable assistance in providing histology slides for rereading; and Alexandra Barratt for constructive comments on a draft of this paper.

Contributors: ED participated in the design, development, and conduct of the study; entered data; coordinated analyses; wrote drafts of the paper; and reviewed the paper. She is guarantor. LI developed the methodological approach to the study and designed the study, supervised the conduct of the study, reviewed analyses, interpreted results, and participated in writing and reviewing the paper. PM developed the methodological approach to the study, designed the study; directed, carried out, and reviewed analyses; interpreted results, and participated in writing and reviewing the paper. SFC had a major role in data management and carried out analyses. JD'A assisted in data management and statistical analyses. AR participated in the development of the study design and managed the day to day running of the study, collection of data, and transference of data; and participated in the reviewing of the paper. AF initiated the study; participated in the development of the methodological approach and study design, the day to day running of the study, the collection and transference of data, rereading of the histology slides, over-viewing the analysis of the data, and writing and reviewing the paper.

Funding: This work was supported in part by grants (Nos 211205 and 402764) from the National Health and Medical Research Council, Australia. The funding source had no involvement in the study design, data collection, analysis, data interpretation, writing of the report, or decision to publish this work. Ethical approval: The study was approved by the ethics committee of the Cancer Institute of New South Wales and by the University of Sydney Human Research Ethics Committee.

1 Davey E, Barratt A, Inwig L, Chan SF, Macaskill P, Mannes P, et al. Effect of study design and quality on unsatisfactory rates, cytology classifications, and accuracy in liquid-based cytology versus conventional cervical cytology: a systematic review. Lancet 2006;367:122-32.

2 Medical Services Advisory Committee of Australia. Liquid based cytology for cervical screening. MSA ref $12 a$ assessment report. Canberra, 2002. www.msac.gov.au/internet/msac/publishing.nsf/ Content/ref12a-1/\$FILE/msacref12a.pdf (accessed 7 Jul 2006).

3 Chock C, Irwig L, Berry G, Glasziou P. Comparing dichotomous screening tests when individuals negative on both tests are not verified. J Clin Epidemiol 1997;50:1211-7.

4 Irwig L, Macaskill P, Farnsworth A, Wright RG, McCool J, Barratt A, et al. A randomised crossover trial of PAPNET for primary cervical screening. J Clin Epidemiol 2004;57:75-81.

5 Commonwealth Department of Human Services and Health. Australian government. Guidelines for the management of women with screen detected abnormalities. Report by the National Health and Medical Research Council for the organised approach to preventing cancer of the cervix. Canberra, 1994.

6 Biscotti CV, Dawson AE, Dziura B, Galup L, Darragh T, Rahemtulla A, et al. Assisted primary screening using the automated ThinPrep imager system. Am J Clin Pathol 2005;123:281-7.

7 Dziura B, Quinn S, Richard K. Performance of an imaging system vs manual screening in the detection of squamous intraepithelial lesions of the uterine cervix. Acta Cytol 2006;50:309-311. 
8 Australian Institute of Health and Welfare. Australian Government. Cervical cancer screening in Australia 2002-2003. AlHW catalogue No 26. Cancer series No 31. Canberra, 2005. www.aihw.gov.au/ publications/can/csa02-03/csa02-03-c03.pdf (accessed 7 Jul 2006).

9 Roberts JM, Gurley AM, Thurloe JK, Bowditch R, Laverty CR. Evaluation of the ThinPrep Pap test as an adjunct to the conventional Pap smear. Med J Aust 1997;167:466-9.

10 Bergeron C, Bishop J, Lemarie A, Cas F, Ayivi J, Huynh B, et al. Accuracy of thin-layer cytology in patients undergoing cervical cone biopsy. Acta Cytol 2001;45:519-24.

11 Ferris DG, Heidemann NL, Litaker MS, Crosby JH, Macfee MS. The efficacy of liquid-based cervical cytology using direct-to-vial sample collection. J Fam Pract 2000;49:1005-11.

12 Laverty CR, Farnsworth A, Thurloe JK, Grieves A, Bowditch R. Evaluation of the CytoRich slide preparation process. Anal Quant Histol 1997;19:239-45.
13 Wilbur DC, Facik MS, Rutkowski MA, Mulford DK, Atkison KM. Clinica trials of the CytoRich specimen-preparation device for cervical cytology. Preliminary results. Acta Cytol 1997;41:24-9.

14 Sherman ME, Mednoza M, Lee K, Ashfaq R, Birdsong GG, Corkill ME, et al. Performance of liquid-based, thin-layer cervical cytology: correlation with reference diagnoses and human papillomavirus testing. Mod Pathol 1998;11:837-43.

15 Melnikow J, Nuovo J, Willan AR, Chan BK, Howell L. Natural history of cervical squamous intraepithelial lesions: a meta-analysis. Obstet Gynecol 1998;92:727-35.

16 Roberts JM, Thurloe JK, Bowditch RC, Humcevic J, Laverty CR. Comparison of ThinPrep and pap smear in relation to prediction of adenocarcinoma in situ. Acta Cytol 1999;43:74-80.

17 Davey E, Irwig L, Macaskill P, Chan SF, D'Assuncao J, Richards A, et al. Cervical cytology reading times: a comparison between ThinPrep imager and conventional methods 2007 (in press).

Accepted: 3 May 2007 